\title{
O olhar supervisivo na perspectiva da ativação de processos de mudança
}

\section{| ${ }^{1}$ Leandro Marcial Amaral Hoffmann, ${ }^{2}$ Lilian Koifman |}

Resumo: O presente estudo objetiva contribuir para a discussão de algumas das competências necessárias ao processo de supervisão em saúde: competência político-gerencial, com ênfase na gestão participativa; competência no cuidado em saúde, com ênfase na integralidade; e competência educacional, com ênfase nas metodologias ativas de ensino e aprendizagem. O desenvolvimento dessas habilidades precisa ser contemplado no processo de formação e educação permanente em saúde, bem como, em especial, a reflexão sobre o caráter transformador do processo de supervisão.

> Palavras-chave: supervisão; metodologias ativas de ensino-aprendizagem; integralidade do cuidado; gestão participativa.

\author{
1 Departamento de \\ Planejamento em Saúde, \\ Instituto de Saúde da \\ Comunidade, Universidade \\ Federal Fluminense. Endereço \\ eletrônico: leandrohoffmann@ \\ id.uff.br \\ 2 Departamento de \\ Planejamento em Saúde, \\ Instituto de Saúde da \\ Comunidade, Universidade \\ Federal Fluminense. Endereço \\ eletrônico: liliankoifman@ \\ hotmail.com
}




\section{Introdução}

Este artigo apresenta reflexão a partir de experiência na tutoria do curso de Ativação de Processos de Mudança na Formação Superior de Profissionais de Saúde, daqui para frente citado como curso de Ativadores de Mudança. Os ministérios da Educação e da Saúde promoveram debate sobre a mudança na formação de profissionais de saúde, lançando, em 2004, o "Aprender SUS", política que reforça a necessidade de articulação entre o processo de formação em saúde e o SUS. O curso de Ativadores de Mudança foi concebido nesse contexto de transformação com a implantação das diretrizes curriculares nacionais para os cursos de saúde e a adoção da integralidade como eixo norteador dos processos de formação. Objetivamos contribuir com foco na discussão das competências necessárias ao desenvolvimento da atuação do supervisor em saúde, compreendido como agente ativador de mudanças.

Supervisão, Educação, Gestão e Cuidado são conceitos fundamentais para a formação profissional na área da saúde. A questão central deste artigo propõe a discussão do conjunto de competências necessárias ao processo de supervisão em saúde. O manual do especializando do curso de Ativadores de Mudança define competência como "[s]íntese dialogada dos diversos elementos que compõem uma determinada prática, qualificada e contextualizada” (BRASIL, 2005). As competências discutidas na formação do profissional ativador se aproximam muito da reflexão proposta por este trabalho, podendo ser compartilhada a definição de ativador de mudança apresentada no manual citado para o que se idealiza como perfil profissional do supervisor:

Um personagem que traz, no próprio nome, duas palavras muito significativas. Ativar, diz o dicionário, é tornar-se ativo. Intensificar(-se). Ativar ou intensificar algo, mas também se intensificar. Transformar-se a partir de uma prática que só se realiza plenamente no encontro com o outro. Transformar, mas também se transformar. Construir e construir-se. [...] Construir cidadania, justiça e solidariedade. Não há mudança sem transformação social. $\mathrm{O}$ ativador de mudança nasce como um agente com o compromisso de transformação social. (BRASIL, 2005).

Para a construção da concepção da competência supervisiva, procuramos focar as três habilidades desenvolvidas durante o curso de ativadores de mudança: competência político-gerencial, com ênfase na gestão participativa; competência do cuidado em saúde, com ênfase na integralidade; e competência educacional, com ênfase nas metodologias ativas de ensino e aprendizagem. 


\section{O olhar supervisivo regulador}

Recorrendo à etimologia da palavra supervisão, temos o sentido de um olhar de cima, dando uma ideia de visão global (super = sobre; visão = ação de ver). Tratase de um olhar técnico, especializado, que pressupõe a atuação de um profissional experiente no sentido da produção de resultados satisfatórios na atividade de outros indivíduos sob sua responsabilidade profissional (ANDRADE, 1976, p.9).

Uma das representações predominantes do processo de supervisão originase da influência taylorista e define o supervisor como o instrumento da execução de políticas centralmente definidas, funcionando como o verificador do cumprimento dessas políticas (ALARCÃO, 2005, p.11). Nesse sentido, a supervisão visa à impressão da direcionalidade e racionalidade gerencial ao processo de trabalho. O supervisor garante a materialização da vontade gerencial ajustando a execução técnica e administrativa aos padrōes e metas previamente definidos pelas instâncias de poder (NUNES, 1986, p.468).

A esse olhar supervisivo - definido historicamente como função de controle e fiscalização, portador de superpoderes de orientação e regulação - vem-se contrapondo uma associação entre avaliação e educação, no sentido de uma "coconstrução" com o supervisor, integrando o coletivo de profissionais e o processo de supervisão e adquirindo o caráter de convisão (REIS, 2004, p.494). Essa nova modalidade de supervisão pressupõe uma concepção problematizadora, ancorada na reflexão crítica sobre a prática baseada numa relação de autonomia, respeito e ética, no sentido de colaboração e construção coletiva, enfatizada na seguinte citação:

\footnotetext{
Confirmam-se, então, a ideia e o princípio de que o supervisor não é um "técnico" encarregado da eficiência do trabalho e, muito menos, um "controlador" de "produção"; sua função e seu papel assumem uma posição social e politicamente maior de líder, de coordenador, que estimula o grupo à compreensão - contextualizada e crítica - de suas ações e, também, de seus direitos (RANGEL, 2005, p.12)
}

\section{O olhar supervisivo e a gestão participativa}

O conceito de objetivo comum, de Senge (1990), pode ser um caminho na construção de uma concepção participativa ou visão compartilhada enquanto instrumento de gestão. Segundo esse autor, os objetivos pessoais são quadros ou imagens que as pessoas carregam nas suas mentes e corações. O objetivo comum 
representa um sentimento de coletividade que as pessoas de uma mesma empresa carregam e que permeia a organização e dá coerência às diversas atividades. Os objetivos comuns nascem sempre dos objetivos pessoais e levam tempo para emergir. Esse é o tempo da troca, da escuta, da tolerância, da compaixão, da construção coletiva da identidade de grupo, quando os indivíduos não só se sentem livres para expressar sua opiniāo, como também aprendem a ouvir a dos outros, e desse aprendizado surgem novos pontos de vista possíveis. A palavrachave nesse processo é comprometimento, diferentemente de obediência, pois o comprometido não age de acordo com as regras do jogo, ele é responsável pelo jogo. O estabelecimento desse processo é indispensável para que uma instituição cumpra seus objetivos.

Trazendo essa reflexão para o processo de supervisão, é fundamental que a relação entre supervisores e supervisionados seja processada de forma horizontal. Segundo Gramsci (CASTRO; CAMPOS, 2003), a capacidade de direção é a habilidade e a potência para compor consensos, alianças e realizar projetos. Num contexto democrático, a construção de capacidade de direção se dá entre o conjunto de pessoas de um coletivo, e não somente entre sua cúpula. $\mathrm{O}$ compartilhamento dessa habilidade contribui concretamente para a diminuição da distância entre governantes e governados, e também para a socialização do poder. Para que isso ocorra, é necessário um trabalho contínuo dos sujeitos e das instituições numa ação de interferência e modificação recíproca e reiterada. A prática democrática é, pois, um produto social. Depende da correlação de forças, do confronto entre movimentos sociais e poderes instituídos, bem como da capacidade social de se construírem espaços de poder compartilhado ou rodas.

A supervisão participativa permite que supervisores e supervisionados contribuam para a definição e aperfeiçoamento de normas, padrões e protocolos de atendimento e estabelecimento de "pactos" no sentido de promover a qualidade da atenção e a resolutividade dos problemas de saúde.

O conceito de "empoderamento" (empowerment), embora não tenha sido concebido neste contexto, pode ser apropriado para essa reflexão. O empoderamento é o processo no qual indivíduos, grupos sociais e organizações passam a ter mais controle sobre seus próprios destinos (VALLA, 1999, p.10 ).

$\mathrm{O}$ empowerment, como processo e resultado, é visto como emergindo em um processo de ação social no qual os indivíduos tomam posse de suas próprias vidas pela interação com outros indivíduos, gerando pensamento crítico em relação à realidade, favo- 
recendo a construção da capacidade social e pessoal e possibilitando a transformação

de relaçôes de poder (ANDRADE, 2002, p.928).

Assim sendo, a concepção da supervisão, enquanto processo de empoderamento, deve envolver tanto componentes individuais como coletivos com participação ativa e crítica, no sentido de desenvolver as competências necessárias para que se obtenham reais transformações. $\mathrm{O}$ empoderamento poderá efetivar-se, na prática, através da construção das chamadas "redes sociais", com o compartilhamento de informaçôes, a solidariedade em momentos de crise, a habilidade para enfrentamento de problemas, a presença em eventos políticos, sociais, culturais e de apoio comunitário, entre outros. Possibilitar a tomada de decisões de maneira participativa é um dos passos mais importantes na geração de novas relaçôes entre governo, prestadores de serviços e as comunidades.

\section{O olhar supervisivo e a integralidade do cuidado}

Cuidar é mais que um ato; é uma atitude, de zelo e de desvelo. Representa uma atitude de ocupação, preocupação, de responsabilização e de envolvimento afetivo com o outro (BOFF, 1999, p.33).

Retomando Senge (1990), podemos afirmar que o objetivo comum que deve ser desenvolvido na área de saúde perpassa o sentido da integralidade do cuidado. Compreende-se a integralidade como um termo polissêmico, com diferentes sentidos e usos (MATTOS, 2006). A definição constitucional diz que "integralidade é a integração de atos preventivos, curativos, individuais e coletivos, em cada um dos níveis de complexidade" (PINHEIRO apud GONZALES; ALMEIDA, 2010). Outro sentido para ação integral associa-se ao tratamento digno, respeitoso, com qualidade, acolhimento e vínculo, através do estabelecimento com o outro de uma relação construtiva e inclusiva, constituindo uma relevante concepção humanizadora.

Cecílio (2006, p.113) postula que a luta pela equidade e integralidade implica, necessariamente, repensarmos aspectos importantes da organização dos processos de trabalho, gestão, planejamento e construção de novos saberes e práticas em saúde. Ele propõe essa reflexão a partir da organização de quatro grandes conjuntos de necessidades: ter boas condiçôes de vida; ter acesso e poder consumir toda tecnologia de saúde capaz de melhorar e prolongar a vida; criar vínculos entre usuário e uma equipe ou profissionais; ter graus crescentes de 
autonomia no seu modo de levar a vida. Essas questôes são fundamentais na construção da integralidade do cuidado, e nos levam a concluir que a organização do sistema de saúde é um dos sentidos do cuidado, através da regionalização e hierarquização da atenção, e também do estabelecimento de protocolos de referência e contrarreferência com resolutividade, da facilitação do acesso e da humanização do atendimento.

Sobre a integralidade, Cecílio (2006, p.116) conclui: "No encontro do usuário com a equipe, haveriam de prevalecer, sempre, o compromisso e a preocupação de se fazer a melhor escuta possível das necessidades de saúde trazidas por aquela pessoa que busca o serviço". Concordando com o autor, entendemos que o foco da gestão, da organização da atenção e da capacitação dos trabalhadores deve voltar-se para a capacidade de escuta e atenção às necessidades de saúde.

Segundo Ruben Mattos (2006, p.41) “a noção de 'imagem objetivo’ tem sido usada na área de planejamento para designar certa configuração de um sistema ou de uma situação que alguns atores na arena política consideram desejável”. Apesar de sua aproximação com o conceito de utopia, o autor destaca a possibilidade e viabilidade de sua concretização. Nesse sentido, precisamos identificar o que se deseja construir a partir daquilo que existe, ou seja, "como" e para "onde" queremos ir. Partimos de uma crítica à realidade, um incômodo e indignação com o que existe, e isso nos leva à busca de um sonho com outra realidade. No desenvolvimento da competência para o cuidado, a questão do "onde gostaria de chegar" vai sendo construída a partir das reflexões sobre integralidade, humanização do atendimento, acolhimento e resolutividade. Esse deve ser o foco de atenção de supervisores, educadores e profissionais de saúde: cultivar o espírito cuidador.

A grande reflexão que permeia a questão do cuidado é a alteridade na relação com o outro, no sentido de sempre nos colocarmos no seu lugar, compreendendo que o cuidado que precisamos oferecer deve ser equivalente ao que buscamos receber. Nesse sentido, nosso caminho de cuidado deve buscar a humanização da atenção, a construção de vínculos, o acolhimento, a formação de redes de cuidado, a garantia de acesso, a integralidade com resolutividade. Pensar em "acolhimento" em saúde é sair da dimensão meramente clínica e técnica e incluir a dimensão humana nas relações profissionais. É desenvolver a capacidade de tolerância às diversidades, assim como da "escuta solidária" comprometida com 
a necessidade do outro e com a construção de sua autonomia. Significa, antes de

tudo, a capacidade de desejar ao outro o que se deseja para si mesmo, colocando-se em seu lugar. Significa também retomar os conceitos de tolerância e compaixão. Na definição de Paulo Freire:

Ser tolerante não é ser conivente com o intolerável, não é acobertar o desrespeito, não é
amaciar o agressor, disfarçá-lo. A tolerância é a virtude que nos ensina a conviver com o
diferente, a respeitar o diferente e a aprender com o diferente. Consentir a convivência,
não muito desejada, de meu contrário, não é tolerância. Isto é hipocrisia. Hipocrisia é
defeito, desvalor. Tolerância é virtude. (FREIRE, 1996, p.59)

O cuidado é, de certa forma, um eterno exercício de tolerância e compaixão, na tentativa de se compreender o outro e de se colocar no lugar do outro. Percebo, cada vez mais, que esse deve ser o olhar de todo ser humano, em especial o olhar cuidador, pois a compaixão do olhar abre as portas para que os sujeitos viabilizem a possibilidade de construção de uma sociedade mais justa, equilibrada e solidária.

\section{O olhar supervisivo e as metodologias ativas de ensino e aprendizagem}

O olhar supervisivo, antes de tudo, é um olhar educador. Esse olhar necessariamente precisa estar vinculado a uma reflexão crítica sobre a realidade (FREIRE, 1999). É através da busca ativa de conhecimentos para dar resposta a uma pergunta, a um problema ou a uma situação vivenciada, que vamos apropriando-nos de instrumentos do conhecimento para aprender a aprender ao longo da vida. Segundo Perrenoud (1999), a prática reflexiva e a participação crítica são concomitantemente os objetivos e as maiores alavancas do processo de aprendizagem.

As metodologias ativas de ensino-aprendizagem estão fundamentadas no princípio da autonomia. São focadas no educando como centro da aprendizagem e são concebidas através de uma relação dialógica entre sujeitos que permite a construção de novos conhecimentos e a transformação da realidade.

A metodologia ativa exige a problematização, a pesquisa e a elaboração própria, em que o sujeito participa e se envolve em um processo intermitente de investigação e discussão coletiva, buscando a produção de conhecimentos (DEMO, 2004). A aprendizagem deve ser significativa, relacionada às experiências anteriores e vivências pessoais, permitindo a formulação de problemas significativos que motivam o aprendizado. Isso possibilita o estabelecimento de uma rede de relaçôes entre fatos, objetos, acontecimentos, noções e conceitos, contribuindo 
para a utilização do que é aprendido em diferentes situações. Para Rogers (1986), o que torna significativa a aprendizagem é o reconhecimento pelo sujeito educando de um problema ou assunto como relevante para seus propósitos e para sua vida. Berbel (1998) pondera que a construção dos problemas deve focar as competências necessárias para o enfrentamento de situações reais, através do processo de reflexão e teorização. Problematizar, portanto, seria para além de formular questôes ou perguntas, exteriorizar conflitos que o problema traz de forma intrínseca e que o sustentam.

$\mathrm{Na}$ perspectiva da aprendizagem significativa, o aprender possui um caráter processual, dinâmico, exigindo a participação do educando nas atividades de ensino para garantir o aprofundamento dos significados elaborados, enquanto requer do educador o exercício contínuo do trabalho reflexivo, da disponibilidade para a pesquisa, para o acompanhamento e avaliação do processo de aprendizado crítico, o que frequentemente pressupõe a ocorrência de situações imprevistas, novas e desconhecidas. Esse processo necessita ser fundamentado a partir de relaçôes dialógicas horizontais entre atores que compartilham cada vez mais parcelas de responsabilidade e comprometimento.

$\mathrm{O}$ educando precisa assumir um papel cada vez mais ativo, abandonando a posição passiva de mero receptor de conteúdos, e caminhar na busca de informações consideradas relevantes, adequadas à resolução dos problemas e aos objetivos de aprendizagem. O educador, também denominado tutor nessa perspectiva de metodologia ativa, precisa desenvolver novas habilidades, como a vontade e a capacidade de permitir ao educando participar ativamente de seu processo de aprendizagem.

Fernandes (2003) resumea missão da metodologiaativa comodesenvolvimento da competência de "aprender a aprender", englobando "aprender a conhecer”, no sentido de aproveitar as oportunidades oferecidas pela educação durante toda a vida, "aprender a fazer", a aquisição de competências que permitam aos sujeitos o enfrentamento de diversas situações e o trabalho em equipe nas experiências sociais; "aprender a conviver", compreender o outro, percebendo e respeitando a pluralidade e a diversidade; e "aprender a ser", conceber a integralidade do ser humano em seu aspecto físico, biológico, psíquico, espiritual, cultural, social e histórico. Dessa forma, garante-se a formação de um sujeito crítico, criativo, com conhecimento da realidade, com autonomia e discernimento, 
pautando sua atuação na sensibilidade, no comprometimento social, na ética, na qualidade, na eficiência e na resolutividade.

O olhar supervisivo educador precisa caminhar também na construção de experiências e oportunidades inovadoras de ensino-aprendizagem que possibilitem a capacidade de agir frente às diferentes situações: saber agir ressignificando a prática e dando suporte para a transformação da realidade.

\section{A experiência e os desafios da utilização das metodologias ativas de ensino e aprendizagem em saúde}

A partir das reflexões teóricas abordadas até agora no artigo, buscaremos descrever uma experiência prática, fruto de nossas atividades e vivências no exercício da docência no campo da Saúde Coletiva no Instituto de Saúde da Comunidade (ISC), da Universidade Federal Fluminense. Trata-se de relato da formação em saúde à luz dos reflexos produzidos pelas políticas de formação lançadas ao longo dos últimos anos.

A opção pelas disciplinas de campo, com momentos prioritariamente em observação e atuação prática, tem sido adotada como estratégia em diversos cursos de graduação em saúde. O ISC, sintonizado com os movimentos políticos que vêm promovendo constantes reflexões sobre o tema da formação, acumulou experiência na consolidação local de estratégias discutidas no campo da formação em saúde. Citamos como exemplo a reforma curricular de Medicina, em 1992, que privilegiou a inserção dos estudantes, desde o início do curso, em rede hierarquizada de serviços, ampliando a participação dos alunos em atividades práticas (SAIPPA-OLIVEIRA et al., 2005).

A disciplina objeto de nosso relato é Trabalho de Campo Supervisionado 1 (TCS 1), que se constrói na busca da diversificação de cenários de ensinoaprendizagem, a partir da articulação com disciplinas teóricas, com o campo de prática das profissóes da área da saúde e com o desafio de tecer uma rede de saberes centrados na integração aprendizagem-extensão-pesquisa. TCS 1 é concebida a partir de metodologias ativas de ensino-aprendizagem e propõe trabalhos em pequenos grupos, nos quais os alunos do primeiro ano do curso de Medicina visitam diversos espaços e instituições, orientados por preceptores (docentes na maioria), que atuam como supervisores. A disciplina busca promover a reflexão a partir da prática com a utilização de alguns temas disparadores como saúde mental, 
saúde da mulher, maternidade, saúde do homem, envelhecimento, infância, álcool e outras drogas, pessoas com deficiência, integralidade e AIDS, entre outros. Para isso, utiliza como referenciais questôes de saúde, cultura e integralidade.

Como relatado em outros trabalhos (SAIPPA-OLIVEIRA et al., 2004; 2005; MARCH et al., 2006; KOIFMAN; WONG UN, 2008), a disciplina tem como objetivos: a caracterização qualitativa e quantitativa - tanto ambiental e populacional quanto psicossocial - dos cenários, nos níveis local e municipal; promover a experiência com trabalhos de grupos; promover o contato com espaços de vivências do ato de cuidar, destacando-se as dimensões humanas, culturais, sociais e políticas; e observar como a integralidade da atenção à saúde se realiza em cada campo - cotidiano, saberes e práticas do cuidado (acolhimento e responsabilização, vínculo, interinstitucionalidade, autonomia do usuário e resolutividade).

A aproximação com a prática desde o começo do curso ajuda o aluno a compreender melhor a atuação do profissional de saúde e as dificuldades existentes no campo (KOIFMAN; WONG UN, 2008).

O trabalho em pequenos grupos, a relação professor-aluno pautada no diálogo, a avaliação durante todo o percurso (e não somente ao final do semestre), o estímulo à participação, à criatividade e à troca de experiências contribuem e impactam positivamente no aprendizado. O papel do docente como supervisor do processo e não centralizador de todas as decisões estimula a reflexão do estudante no intuito de exercitar essa habilidade em sua futura prática profissional.

Para os estudantes, a metodologia utilizada na disciplina é surpreendente. A organização em grupos pequenos, dentro dos quais as leituras de artigos científicos são dinamizadas, com conhecimento compartilhado e o planejamento das visitas feito de forma participativa, promovem sensação de liberdade nos alunos, que muitas vezes não sabem o que fazer com essa autonomia. Para alguns, isso representa um estímulo, levando-os até a faltar outras aulas para realizar tarefas ou visitas para o trabalho de campo. Em outros casos, sentem tanta liberdade que acabam atendendo mais a outras disciplinas que os pressionam e exigem resultados quantitativos (KOIFMAN; WONG UN, 2008).

As relações de poder entre o professor e o aluno induzem ao autodisciplinamento. Deste modo, ambos os agentes aperfeiçoam seus papéis e passam a incutir em seus atos novas formas de pensar a realidade, novas técnicas de estudo, ensino e aprendizagem, sem dissociar, no entanto, o método 
e o conteúdo. Logo, a dicotomia de poderes avança para a construção de um domínio que legitime o aprendizado e a instituição contínua de metodologias inovadoras. Da mesma forma como, na relação do profissional de saúde com o usuário, o caminho do cuidado deve buscar a humanização da atenção através da construção de vínculos, acolhimento, formação de redes de cuidado, garantia de acesso, integralidade com resolutividade, a relação supervisor-aluno deve apontar para o estabelecimento de relaçóes humanizadas.

A prática do cuidado entendida como valor nos leva a pensar a prática docente nos cursos de formação em saúde, compreendendo-a enquanto orientadora e comprometida com a materialização das formas de expressão do cuidado no cotidiano das práticas de saúde, seja por meio de atos na gestão, seja nas práticas do trabalho em saúde, afirmando assim o compromisso com os princípios do SUS, dentre os quais se destaca a integralidade (SAIPPA-OLIVEIRA et al., 2007).

Entendemos, portanto, que a relação supervisor-aluno (professor-aluno), estabelecida nos processos educativos (em qualquer cenário de aprendizagem) tem papel marcante na consolidação do modo de agir em saúde desses futuros profissionais.

\section{Considerações finais: o olhar supervisivo ativador}

A missão do olhar supervisivo pode ser resumida e conceituada através da reflexão do significado da expressão ativador de mudanças. Esse termo polissêmico qualifica um sujeito educador e "coconstrutor" de um novo saber na busca de transformação da realidade social. Gestão participativa, integralidade do cuidado e metodologias ativas de ensino e aprendizagem precisam integrar o processo de formação e educação permanente em saúde.

A busca ativa e a produção qualificada na área de ensino-aprendizagem, ancoradas na vivência prática, seja na área de gestão, cuidado ou formação, trazem uma contribuição significativa para os campos da Educação e da Saúde Coletiva. A diversificação de cenários de ensino e aprendizagem contribui efetivamente para a qualificação do SUS, pela formação de profissionais adequados às suas demandas e necessidades, e também através do desenvolvimento de projetos de extensão universitária.

As teorias acerca das competências do profissional educador-ativador-cuidadorsupervisor devem contribuir para o questionamento sobre o seu papel enquanto 
sujeito transformador. E é a compreensão desse papel a principal competência a ser desenvolvida. A partir dessa compreensão é preciso agregar colaboradores, ativar a mudança e construir coletivamente a transformação.

Finalizamos este trabalho ${ }^{1}$ citando o manifesto de educadores apresentado no Fórum Social Mundial em Porto Alegre, o qual exalta a importância do processo educativo na transformação da sociedade:

No século que findou, dois projetos de sociedade fracassaram relativamente ao processo civilizatório: um porque privilegiou o eu, eliminando o nós; o outro porque privilegiou o nós desconsiderando o eu. Neste novo século, confrontam-se dois projetos antagônicos de sociedade: um subordina o social ao econômico e ao império do mercado, outro prioriza o social. Faz-se necessário construir um projeto de sociedade onde o ser humano seja resgatado na sua plenitude de eu e nós, com base na prioridade do social sobre o econômico. Para que este novo mundo seja possível, é necessário que toda humanidade entenda e aceite a educação transformadora como pré-condição. Essa educação tem como pressupostos os princípios de que ninguém ensina nada a ninguém e de que todos aprendem em comunhão, a partir da leitura coletiva do mundo (GADOTTI, 2001, p. 18).

\section{Referências}

ALARCÃO, I. Do olhar supervisivo ao olhar sobre a supervisão. In: RANGEL, M. (Org.). Supervisão pedagógica: princípios e práticas. Campinas: Papirus, 2005.

ANDRADE, G.R.B.; VAITSMAN, J. Apoio social e redes: conectando solidariedade e saúde. Ciência \& Saúde Coletiva, v.7, n.4, p.925-934, 2002.

ANDRADE, N.V. Supervisão em educação: um esforço para melhoria dos serviços educacionais. Rio de Janeiro: Fename, 1976.

BERBEL, N.A.N. A problematização e a aprendizagem baseada em problemas. Interface -Comum. Saúde Educ. Botucatu, v.2, p.139-154, 1998.

BOFF, L. Saber cuidar; ética do humano; compaixão pela terra. Petrópolis: Vozes, 1999.

BRASIL. Ministério da Saúde. Curso de Especialização em Ativação de Processos de Mudança na Formação Superior de Profissionais de Saúde: caderno do especializando. Rio de Janeiro: Fiocruz, 2008.

CECILIO, L.C.O. As necessidades de saúde como conceito estruturante na luta pela integralidade e equidade na atenção em saúde. In: PINHEIRO, R.; MATTOS, R.A. (Orgs.). Os sentidos da integralidade na atenção e no cuidado à saúde. Rio de Janeiro: Cepesc, 2001. p.115-128. 
DEMO, P. Professor do futuro e reconstrução do conhecimento. Petrópolis: Vozes; 2004.

FERNANDES, J.D. et al. Diretrizes estratégicas para a Implantação de uma Nova Proposta Pedagógica na Escola de Enfermagem da Universidade da Federal da Bahia. Esc. Anna Nery Rev. Enferm., v.56, n.54, p.392-5, 2003.

FREIRE, P. Pedagogia da autonomia: saberes necessários à prática educativa. São Paulo: Paz e Terra, 1996.

. Educação e mudança. São Paulo: Paz e Terra, 1999.

GADOTTI, M. Um legado de esperança. São Paulo: Cortez, 2001.

CASTRO, E.A.B.; CAMPOS, E.M.S. Uma discussão sobre as competências e habilidades de gestores no âmbito do sistema público de saúde. Revista APS, v.6, n.2, p.94-98, 2003.

KOIFMAN, L.; WONG UN, J.A. Construindo saberes recíprocos: ética e técnica na prática educativa em saúde. In: PINHEIRO, R.; MATTOS, R.A. (Orgs.). Cuidar do Cuidado: responsabilidade com a integralidade das ações de saúde. Rio de Janeiro: Cepesc, 2008. p.251-266.

MARCH, C. et al. O currículo de medicina da Universidade Federal Fluminense: revisitando uma experiência. In: PINHEIRO, R.; MATTOS, R.A. (Orgs.). Ensinar Saúde: a integralidade e o SUS nos cursos de graduação na área de saúde. 1ªed. Rio de Janeiro: Cepesc, 2006, p.295-309.

MATTOS, R.A. Os sentidos da integralidade: algumas reflexões acerca de valores que merecem ser defendidos. In: PINHEIRO, R.; MATTOS, R.A. (Orgs.). Os sentidos da integralidade na atenção e no cuidado à saúde. Rio de Janeiro: Cepesc, 2001.

NUNES, T.C.M. A supervisão: uma proposta pedagógica para o setor saúde. Cad. Saúde Pública, v.2, n.4, p.466-476, 1986.

PERRENOUD, P. Formar professores em contextos sociais em mudança. Prática reflexiva e participação crítica. Rev. Bras. Educ., v.2, p.5-21, 1999.

GONZALES, A.D.; ALMEIDA, M.J. Integralidade da saúde: norteando mudanças na graduação dos novos profissionais. Ciênc. saúde coletiva [online], v.15, n.3, 2010. Acesso em: 04 set 2012, p.757-762. Disponível em <http://www.scielo.br/scielo.php?script=sci_ arttext\&pid = S1413-81232010000300018\&lng=en \&nrm =iso>

RANGEL, M. Consideraçôes sobre o papel do supervisor, como especialista em educação, na América Latina. In: - (Org.). Supervisão pedagógica: princípios e práticas. Campinas: Papirus, 2005.

REIS, C.C.; HORTALE, V.A. Programa Saúde da família: supervisão ou “convisão"? Estudo de caso em município de médio porte. Cad. Saúde Pública, v.20, n.2, p.492-501, 2004.

ROGERS, C. Liberdade de aprender em nossa década. Porto Alegre: Artes Médicas, 1986. 
SAIPPA-OLIVEIRA, G.; KOIFMAN, L.; PONTES, A.L.M. As agendas públicas para as reformas e sua releitura no cotidiano das práticas da formação: o caso da disciplina Trabalho de Campo Supervisionado. In: PINHEIRO, R.; MATTOS, R.A. (Orgs.). Construção social da demanda. Rio de Janeiro: Cepesc, 2005. p. 129-145.

. KOIFMAN, L.; MARINS, J.J.N. A busca da integralidade nas práticas de saúde e a diversifcação dos cenários de aprendizagem: o direcionamento do curso de medicina da UFF. In: PINHEIRO, R.; MATTOS, R.A. (Orgs.). Cuidado: as fronteiras da Integralidade. Rio de Janeiro: Cepesc, 2004, p.307-319.

. KOIFMAN, L.; FERNANDEZ, V.S. Reflexôes sobre o papel do docente em saúde na constituição de valores e sentidos sobre o ato de cuidar. In: PINHEIRO, R.; MATTOS, R.A. (Orgs.). Razões públicas para a integralidade em saúde: o cuidado como valor. Rio de Janeiro: Cepesc, 2007, p.166-181.

SENGE, P.M. A quinta disciplina. São Paulo: Best Seller, 1990.

VALLA, V.V. Educação popular, saúde comunitária e apoio social numa conjuntura de globalização. Cad Saúde Pública, v.15, supl., p.7-14, 1999.

\section{Nota}

${ }^{1}$ L.M.A. Hoffmann elaborou a pesquisa e a redação do texto. L. Koifman contribuiu na revisão do artigo e no relato de experiência. 
The supervising look in the perspective of changing processes activation

This study aims to contribute to the discussion of some of the skills necessary to the health supervision process: political and managerial competence, with emphasis on participatory management; competence in health care, with an emphasis on integral care; and educational competence, with emphasis on active teaching and learning methodologies. The development of these skills needs to be covered in the process of training and continuing health education and, in particular, the reflection on the transformative character of the supervision process.

> Key words: supervision; active teaching and learning methodologies; integral care; participatory management. 